\title{
Oral anticoagulants and atrial fibrillation: A South African perspective
}

\author{
D J Laäs, MB ChB; M Naidoo, MB ChB, FCFP, MFamMed, MSc (Sports Medicine), PhD \\ Discipline of Family Medicine, School of Nursing and Public Health, College of Health Sciences, University of KwaZulu-Natal, Durban, South Africa
}

Corresponding author: D Laäs (daniel.j.laas@gmail.com)

This review evaluates the current literature on available oral anticoagulants and atrial fibrillation with specific relevance to the South African (SA) public healthcare sector, focusing on the pharmacology and monitoring of anticoagulants, current guidelines, initiation of treatment and risk stratification, effectiveness of treatment, cost-effectiveness and specific costing implications. The direct-acting oral anticoagulants (DOACs) are superior to warfarin, with dabigatran being the preferred treatment option in patients with non-valvular atrial fibrillation (NVAF). Warfarin is still the preferred anticoagulant in patients with renal failure and prosthetic heart valves and is still the most costeffective anticoagulant in the SA public sector setting. There is a growing body of evidence that demonstrates the advantages of DOACs over warfarin in NVAF. Warfarin will remain the anticoagulant of choice until cheaper generic DOACs become available.

S Afr Med J 2018;108(8):640-646. DOI:10.7196/SAMJ.2018.v108i8.13309

Atrial fibrillation $(\mathrm{AF})$ is the commonest clinically significant arrhythmia and is associated with significant morbidity and mortality. ${ }^{[1]}$ Until recently, treatment options were very limited with the mainstay of treatment being the vitamin $\mathrm{K}$ antagonists (VKAs). The introduction of the direct-acting anticoagulants has changed the playing field by offering patients a choice, but at a price. The majority of South African (SA) patients are still deprived of this choice owing to financial constraints. We therefore set out to review oral anticoagulants and AF with a specific focus on our patient population. The focus of this review is to assist clinicians in their decision-making and prescribing practices.

Anticoagulants are categorised into two large subgroups: those affecting the rapidly flowing arterial systems and those affecting the more stasis-prone venous system. Thrombi in the venous system consist of a fibrin web encasing platelets and red blood cells. In contrast, thrombi in the arterial system consist largely of platelets with less fibrin. Drugs affecting coagulation are classified and subsequently designed to target specific sites of these thrombi. Drugs targeting arterial thrombi include the antiplatelet drugs (aspirin, clopidogrel, abciximab, eptifibatide and tirofiban) and the fibrinolytics (streptokinase and alteplase). Drugs targeting venous or stasis-induced thrombi include the traditional anticoagulants (heparin, low-molecular-weight (LMW) heparins and fondaparinux), the VKAs (warfarin), and more recently the novel or direct-acting oral anticoagulants (DOACs) (dabigatran, rivaroxaban and apixaban). ${ }^{[2]}$

In this review, we focus on the VKA warfarin and the DOACs dabigatran and rivaroxaban and their use in NVAF in the SA state sector. NVAF is common, and with the arrival of the DOACs, doctors in the public sector need to familiarise themselves with these drugs and their risks and benefits.

\section{Methods}

A systematic literature search was conducted of PubMed, Google Scholar and the TRIP database. The following Medical Subject Heading (MeSH) terms were used: 'anticoagulants', 'vitamin $\mathrm{K}$ antagonists', 'warfarin', 'direct or novel acting anticoagulants', 'dabigatran', 'rivaroxaban,' 'apixaban', 'pharmacology', 'monitoring,' 'cost effectiveness', 'atrial fibrillation', 'risk stratification', 'guidelines' and
'South Africa'. Other databases consulted included the universities of Liverpool and California's antiretroviral drug databases, Statistics South Africa, and the Joint United Nations Programme on HIV/ AIDS (UNAIDS) regarding HIV statistics. Printed pharmacology textbooks were also consulted where electronic text was unclear.

Systematic reviews, randomised controlled trials, cohorts and case-control studies were included. Only studies published in English were included. Original research was included then compared with research or study types that best addressed the specific research questions. The research question for each topic in this review revolved around what the current gold standard is and how we can implement it in our setting. When available, SA literature was included. Case studies and case series were excluded, as were studies published in foreign languages and those not related to AF. Research published after 31 December 2017 was not included.

\section{Results and discussion}

To determine whether we can successfully introduce the DOACs in our setting, we reviewed a total of 113 references and included 40 publications that met our inclusion criteria. Of the 40 articles included, seven (see Table 4) directly addressed our research question: Will the use of DOACs be more cost-effective than warfarin for nonvalvular AF (NVAF) in the public healthcare setting in SA? Fig. 1 represents a visual illustration of articles included and excluded. ${ }^{[3]}$

Pharmacology and monitoring of warfarin and DOACs Warfarin is a VKA and coumarin derivative acting on the cyclic interconversion of vitamin $\mathrm{K}$ in the liver. VKAs block $\gamma$-carboxylation of glutamate residues and inhibit vitamin $\mathrm{K}$ reductase. This process results in partially carboxylated and decarboxylated vitamin K-dependent clotting factors (II, VII, IX, X). These proteins lose their procoagulant effect because carboxylation is required to bring about a calcium-dependent conformational change in the coagulation proteins ${ }^{[4]}$ Without this conformational change, coagulation proteins cannot bind to cofactors on phospholipid surfaces and coagulation fails. The anticoagulant proteins $\mathrm{C}$ and $\mathrm{S}$ are also inactivated by this process and can lead to a prothrombotic state, which is in most circumstances overcome by the effect of the VKAs. ${ }^{[5]}$ The intensity of 


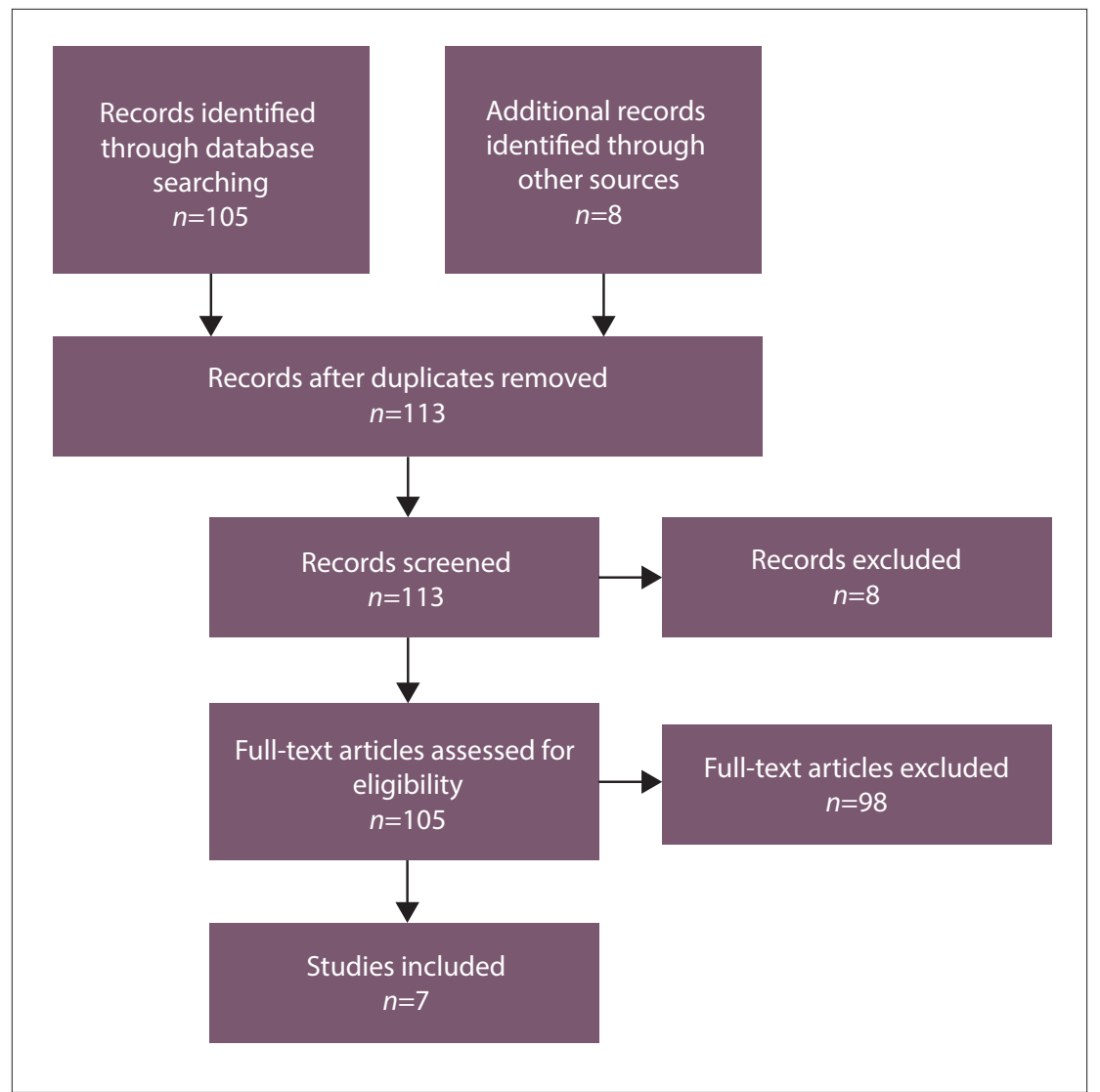

Fig. 1. Flow diagram of literature reviewed to determine the end-point.

coagulation is monitored using the patient's prothrombin time (PT) and is standardised by an international normalised ratio (INR) test. $^{[5]}$ The INR is calculated as follows: ${ }^{[6]}$ $\mathrm{INR}=(\text { patient } \mathrm{PT} / \text { mean normal PT })^{\mathrm{ISI}}$.

Warfarin should be taken once a day, at the same time every day. Two to three doses of warfarin are necessary for the INR to reach the therapeutic range. This delay in effect can be attributed to the different half-lives of the clotting factors. The vitamin K-dependent factors detected by the PT test undergo reduction at a rate proportional to their halflives. Factor VII is reduced first, followed by factors X and II. The mean therapeutic INR is 2.5 (range $2.0-3.0$ ), with the exception of a mitral prosthesis, which requires a mean INR of 3.0 (range 2.5 - 3.5). ${ }^{[7]}$

INR monitoring should be commenced after two to three doses of treatment and differs for inpatients and outpatients. Inpatients require daily INRs until the therapeutic range has been achieved and maintained for 2 days. Outpatients can be monitored every 2 days until a stable INR has been achieved. Once the INR is stable, intervals between monitoring should not exceed 4 weeks. Current guidelines recommended monitoring intervals of up to 12 weeks in stable patients. ${ }^{[7]}$ Evidence suggests that more frequent monitoring results in more time in the therapeutic range (TTR). ${ }^{[8]}$ Patients at an increased risk of thromboembolic events require dual anticoagulation with LMW heparin or unfractionated heparin after being initiated on warfarin, because of warfarin's effect on protein $\mathrm{C}$ and $\mathrm{S}$ and the 2 -3-day delay in reaching the therapeutic range. Dual anticoagulation can be stopped once the INR has been within the desired therapeutic range for 2 days or when two INR measurements taken 24 hours apart are within the therapeutic range. Patients with stable conditions (including chronic AF) can be started on VKAs on an outpatient basis without additional anticoagulant cover at a loading dose of $10 \mathrm{mg}$ for healthy individuals. ${ }^{[7]}$

Warfarin is also known to interact with numerous drugs and with foods such as green leafy vegetables. These vegetables have naturally high vitamin $\mathrm{K}$ levels and interact with VKAs. ${ }^{[9]}$ Various drugs affect warfarin's metabolism, either potentiating or reducing its effectiveness. Warfarin consists of an Sand an R-enantiomer. The S-enantiomer is the more potent of the two and drugs such as clotrimazole and metronidazole, which inhibit its metabolism, potentiate warfarin's effects. ${ }^{[5,10]}$ Drugs affecting the R-enantiomer, such as the proton-pump inhibitor omepra- zole and the $\mathrm{H}_{2}$ antagonist cimetidine, have a lesser effect on PT and INR. Long-term paracetamol and alcohol use have been found to alter the clearance of warfarin, although short-term alcohol use was found to have a negligible effect on PT. Chronic alcohol use increases the clearance of warfarin and lowers the INR. ${ }^{[11]}$ Chronic paracetamol use increases the anticoagulant effect of warfarin through a toxic metabolite that inhibits vitamin $\mathrm{K}$ oxide reductase. ${ }^{[12]}$ Rifampicin, barbiturates, carbamazepine, griseofulvin, aminoglutethimide, nafcillin and dicloxacillin are powerful inducers of warfarin metabolism and decrease its effectiveness. ${ }^{[13]}$

Antiretroviral medication influences warfarin concentration to various degrees, but high-quality, peer-reviewed evidence of the exact mechanisms is lacking. The protease inhibitors appear to decrease the effects of warfarin, with ritonavir decreasing R-enantiomer levels and lopinavir inducing CYP2C9. ${ }^{[14]}$ Nevirapine and efavirenz alter warfarin levels to various degrees through complex mechanisms, and frequent drug monitoring is required. ${ }^{[15]}$ Currently there is little evidence to suggest that the common nucleoside/nucleotide analogues have a clinically significant effect on a patient's INR. ${ }^{[15,16]}$

The DOACs, which include dabigatran, rivaroxaban and apixaban, were designed because of the limitations associated with warfarin use. Dabigatran or the prodrug dabigatran etexilate is a reversible direct thrombin inhibitor and prevents the conversion of fibrinogen to fibrin. ${ }^{[17]}$ Because this drug causes reversible inhibition of thrombin, it leaves a small amount of free active thrombin to assist with haemostasis. ${ }^{[17]}$ Routine drug monitoring is not recommended by the manufacturer or by the American College of Chest Physicians, as dabigatran has a relatively predictable pharmacological profile. Ecarin clotting time can be used to monitor the effect of this drug, but neither the PT nor the activated partial thromboplastin time (aPTT) can be used, as there is no linear correlation between dabigatran concentration and aPTT levels. ${ }^{[18]}$ As dabigatran is renally excreted, some authors do recommend drug monitoring in patients with renal impairment. ${ }^{[19]}$

Rivaroxaban is a direct and reversible inhibitor of factor Xa that inhibits both free and clot-bound factor Xa, resulting in its anticoagulant effect. As with dabigatran no routine drug monitoring is required, although unlike dabigatran, rivaroxaban has a predictable effect on the PT and to a lesser extent the aPTT. ${ }^{[20]}$ Apixaban, like rivaroxaban, is a factor $\mathrm{Xa}$ inhibitor. ${ }^{[20]}$ 


\section{Managing a patient who requires anticoagulation}

Anticoagulation is complex, as there are several indications, agents and dosing regimens to choose from. In the SA public healthcare sector these complexities are exacerbated by our diverse patient populations, some of whom have multiple comorbidities, and limited access to the various anticoagulants available. Numerous international guidelines are available for outpatient anticoagulation and prevention of thromboembolic events. Guidelines that are widely used include the 2012 American College of Chest Physicians (ACCP) (9th edition) $)^{[21]}$ and the 2011 British Journal of Haematology (BJH) guidelines. ${ }^{[22]}$

The $2011 \mathrm{BJH}$ guidelines on oral anticoagulation with warfarin are widely used in SA and are often referenced by the National Health Laboratory Service. Differences between these two guidelines are set out in Table 1. Most clinicians refer to the ACCP guidelines when making a decision on managing patients who require anticoagulation, as these guidelines are more comprehensive than the $\mathrm{BJH}$ guidelines.

There are several noteworthy updates to the 9th edition of the ACCP guidelines, and one that will have a major effect on patient load and expenses is the frequency of INR monitoring. Traditionally patients are seen at 4-week intervals to check whether their INRs are in the therapeutic range, but the update recommends that this may be lengthened to 12 weeks. Patients become eligible for this prolonged follow-up if they have consistently stable INRs without requiring dose adjustment. ${ }^{[7]}$ The implementation of such a recommendation has the potential to significantly decrease cost and patient load on the healthcare system. Our own research has shown that a major driver of cost is number of clinic visits in combination with monthly INRs, and a major driver of patient dissatisfaction is number of consultations and venepunctures. ${ }^{[23]}$ The ACCP guidelines recommend using dabigatran $150 \mathrm{mg}$ twice daily instead of warfarin for treating NVAF for patients at intermediate and high risk for stroke (recommendation 2.1.11, grade $2 \mathrm{~B}$ recommendation and level of evidence). ${ }^{[21]}$
Unfortunately, there are no recent anticoagulation guidelines specific to SA. Implementing North American and European guidelines is difficult in the SA setting owing to the high prevalence of HIV, as these new drugs are poorly studied in this subgroup of patients. In 2016 SA had an estimated 7.1 million people living with HIV, 19\% of the global HIV population, of whom 56\% had access to antiretroviral treatment. ${ }^{[24]}$ This population of patients are at risk of developing deep-vein thrombosis. ${ }^{[25]}$

\section{Risk stratification and initiation of treatment}

Risk stratification is particularly useful in deciding when to initiate treatment in patients with NVAF. Several scoring systems have been devised to better manage patients with NVAF. The two most popular are the $\mathrm{CHA}_{2} \mathrm{DS}_{2}-\mathrm{VASc}$ and $\mathrm{CHADS}$, scores, $\mathrm{CHA}_{2} \mathrm{DS}_{2}$ VASc being the updated scoring system of the original $\mathrm{CHADS}_{2}$ score. $^{[26]}$

Table 2 highlights the different components of the $\mathrm{CHA}_{2} \mathrm{DS}_{2}$ VASc score. $\mathrm{CHA}_{2} \mathrm{DS}_{2}$-VASc is an acronym that helps to determine a patient's annual stroke risk. ${ }^{[2]}$ The maximum score is 9 points.

\begin{tabular}{ll} 
Table 2. $\mathrm{CHA}_{2} \mathrm{DS}_{2}$-VASc score & Score \\
\hline Risk factor & 1 \\
\hline Congestive heart failure (C) & 1 \\
Hypertension (H): Blood pressure consistently & \\
$>140 / 90$ mmHg (or treated hypertension on medication) & \\
Age $\geq 75$ years (A) & 2 \\
Diabetes mellitus (D) & 1 \\
Prior stroke or TIA or thromboembolism (S) & 2 \\
Vascular disease (V) & 1 \\
Age 65 - 74 years (A) & 1 \\
Sex category (female sex) (Sc) & 1 \\
TIA = transient ischaemic attack. &
\end{tabular}

Table 1. Differences between guidelines on anticoagulation with warfarin

\begin{tabular}{|c|c|c|}
\hline & $2011 \mathrm{BJH}$ guidelines ${ }^{[22]}$ & 2012 ACCP guidelines (9th edition) ${ }^{[21]}$ \\
\hline Indications & $\begin{array}{l}\text { VTE, APS, AF, cardioversion, valvular heart } \\
\text { disease and prosthetic valves, peripheral } \\
\text { vascular disease and myocardial infarction } \\
\text { and cardiomyopathy }\end{array}$ & $\begin{array}{l}\text { DVT/PE, AF or atrial flutter, CAD, valvular and } \\
\text { rheumatic heart disease, and prevention of VTE } \\
\text { for orthopaedic surgery }\end{array}$ \\
\hline Initiation of treatment & $\begin{array}{l}\text { No evidence to suggest that a } 10 \mathrm{mg} \text { loading } \\
\text { dose is superior to a } 5 \mathrm{mg} \text { loading dose }\end{array}$ & $\begin{array}{l}\text { In healthy outpatients with VTE, initiating } \\
\text { treatment at a dose of } 10 \text { mg daily for } 2 \text { days } \\
\text { followed by dosing based on INR measurements, } \\
\text { rather than starting with the estimated } \\
\text { maintenance dose, is recommended. This decreases } \\
\text { the number of doses of LMWH and achieves a } \\
\text { therapeutic INR sooner. }\end{array}$ \\
\hline $\begin{array}{l}\text { Management of bleeding and of an } \\
\text { elevated INR without bleeding }\end{array}$ & $\begin{array}{l}\text { Major bleeding } \\
\text { - Administer } 25 \text { - } 50 \mathrm{U} / \mathrm{kg} \text { of four-factor PC } \\
\text { AND } 5 \mathrm{mg} \text { IV vitamin } \mathrm{K} \\
\text { Non-major bleed } \\
\text { - Administer } 1 \text { - } 3 \mathrm{mg} \text { of IV vitamin } \mathrm{K} \\
\text { Non-bleeding patient } \\
\text { - INR } 5.0 \text { - 7.9: withhold } 1 \text { - } 2 \text { doses of } \\
\text { warfarin, reduce maintenance dose and } \\
\text { investigate cause of elevated INR } \\
\text { - INR >8.0: } 1 \text { - } 5 \mathrm{mg} \text { of oral vitamin } \mathrm{K}\end{array}$ & $\begin{array}{l}\text { VKA-associated major bleed } \\
\text { - Rapid reversal with four-factor PC rather } \\
\text { than with plasma, and vitamin K } 5-10 \mathrm{mg} \\
\text { administered by slow IV injection } \\
\text { INR }>10.0 \text { without bleeding } \\
\text { - Oral vitamin K } 2 \text { - } 2.5 \mathrm{mg} \\
\text { INR } 4.5 \text { - } 10.0 \text { without major bleeding } \\
\text { - No evidence to support routine use of vitamin K }\end{array}$ \\
\hline
\end{tabular}


These models incorporate the major risk factors for ischaemic stroke and give an unadjusted ischaemic stroke rate as a percentage per year. ${ }^{[27]} \mathrm{A}$ score of 0 requires no anticoagulation, although there are exceptions to this rule. A score of $\geq 2$ (high risk for thromboembolism) is a strong indication for anticoagulation with either DOACs or VKAs, while there is some controversy regarding a score of 1 (intermediate risk for thromboembolism). Some clinicians choose to anticoagulate all patients with a score of 1 , while others choose to withhold therapy. ${ }^{[28]}$

Patients who qualify for and are initiated on oral anticoagulation have an increased risk of bleeding. This increased risk of bleeding is usually offset by the benefit obtained from thromboembolism risk reduction, although there are certain instances where this is not the case. For this reason, the HAS-BLED scoring system (Table 3) was developed. The HAS-BLED score is a simple and practical score that is used to determine a patient's annual bleeding risk. Oral anticoagulation bleeding risk outweighs the benefits of treatment if the HAS-BLED score exceeds the $\mathrm{CHADS}_{2}$ score in patients with a $\mathrm{CHADS}_{2}$ score $>2$. In patients with a $\mathrm{CHADS}_{2}$ score of 1 , a HAS-BLED score $>2$ should prompt the doctor not to consider oral anticoagulation. ${ }^{[29]}$ The maximum score is also 9 points. Fig. 2 illustrates a practical approach to treating patients with NVAF by combining the HASBLED and $\mathrm{CHA}_{2} \mathrm{DS}_{2}$-VASc scores.

\section{Valvular AF}

Rheumatic and mechanical prosthetic heart valves, with or without comorbid AF, require anticoagulation with VKAs. Dabigatran is contraindicated in patients with prosthetic heart valves, and rivaroxaban and apixaban are unstudied in this population group. The RE-ALIGN trial was stopped during phase two owing to an increase in thromboembolic events and bleeding in the dabigatran subgroup. ${ }^{[30]}$ Investigators have attempted to explain this complication by suggesting that there was an incorrect selection of dabigatran trough levels and a possible decrease in dabigatran's effectiveness during a postoperative hypercoagulable state. ${ }^{[31]}$ A notable exception to this rule is the bioprosthetic valves, which carry a relatively low risk of thrombosis, but there is limited evidence to suggest that some DOACs may be a suitable alternative to conventional anticoagulation in these patients. ${ }^{[32]}$

\section{Effectiveness of the available oral anticoagulants}

The ROCKET-AF, ${ }^{[33]}$ ARISTOTLE ${ }^{[34]}$ and RE-LY ${ }^{[35]}$ studies have found the DOACs to be non-inferior to warfarin, and in some cases superior. Dabigatran $150 \mathrm{mg}$ twice daily was associated with a stroke rate of $1.11 \%$ per year for patients with NVAF compared with a stroke rate of $1.69 \%$ per year for patients on dose-adjusted warfarin $(p<0.001)$. Rates of major bleeding for dabigatran $150 \mathrm{mg}$ and dose-adjusted warfarin appear to be similar, but there is a significantly decreased risk of life-threatening intracranial bleeds with dabigatran $110 \mathrm{mg}(0.12 \% ; p<0.001)$ and $150 \mathrm{mg}(0.10 \% ; p<0.001)$ compared with warfarin $(0.38 \%){ }^{[35]}$

Rivaroxaban showed similar results, with a significant reduction in fatal bleeds in comparison with warfarin $(0.2 \% \mathrm{v}$. $0.5 \% ; p=0.003)$. An important finding of the ROCKET-AF trial was the TTR for patients on warfarin, which was only $55 \%{ }^{[33]}$ Some authors have mentioned that this is a confounding factor in ROCKETAF. There is no internationally acceptable TTR for clinical trials, although Connolly et al. ${ }^{[36]}$ showed that there is little benefit of oral anticoagulation over conventional antiplatelet therapy if the TTR is $<58-65 \%$. A similar comment can be made when evaluating the ARISTOTLE trial in which 18201 patients were enrolled. Apixaban was found to be more effective than warfarin in preventing stroke and systemic embolism with lower rates of bleeding. Patients on warfarin had a mean TTR of $62 \%$ and a median TTR of 66\%. ${ }^{[34]}$ Possible explanations for warfarin's TTR in this study include noncompliance, drug-drug interaction, drugfood interactions and patient comorbidities.

The DOACs require less monitoring and have fewer drug interactions than the VKAs, but they do have distinct disadvantages.

\begin{tabular}{ll} 
Table 3. HAS-BLED score & \\
\hline Risk factor & Score \\
\hline Hypertension (H) & 1 \\
Abnormal (A) renal and liver function (1 point each) & 1 or 2 \\
Stroke (S) & 1 \\
Bleeding history (B) & 1 \\
Labile INRs (L) & 1 \\
Elderly (E) & 1 \\
Drugs (D) or alcohol (1 point each) & 1 or 2 \\
INR = international normalised ratio. &
\end{tabular}

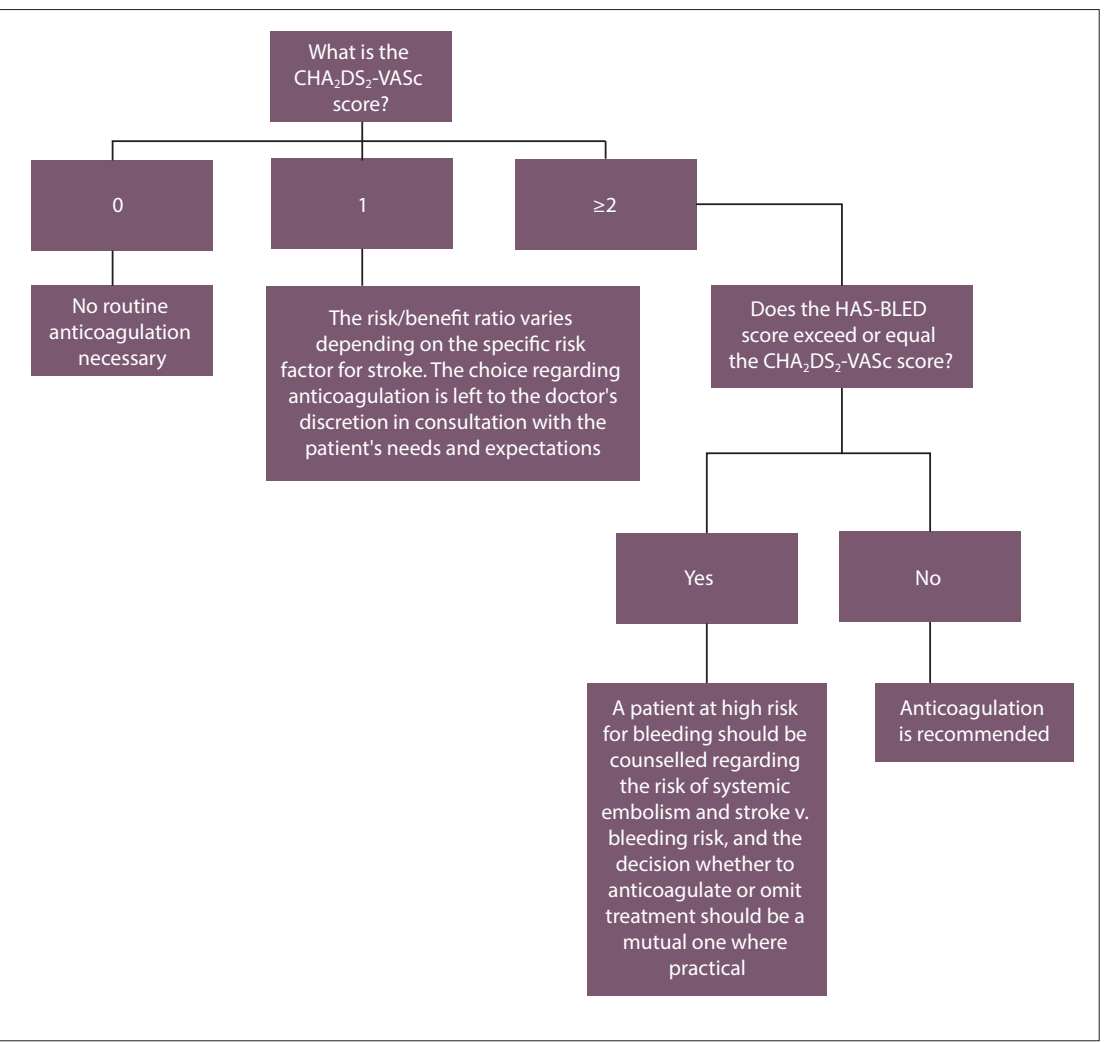

Fig. 2. A practical approach to anticoagulation in non-valvular atrial fibrillation. 
A major concern for healthcare providers is the absence of a readily available antidote or reversal agent. A reversal agent for dabigatran is available in the form of idarucizumab (Praxbind), a monoclonal antibody, but there are none for any of the factor Xa inhibitors. ${ }^{[37]}$ Currently Praxbind is available in SA as a section 21 drug at a cost of ZAR32 000 including value-added tax. Section 21 of the Medicines and Related Substances Control Act (No. 101 of 1965) authorises the sale of unregistered orthodox medicine, complementary medicine, veterinary medicine or devices for certain purposes. ${ }^{[38]}$ Management of major bleeds revolves around haemodialysis, administering an antifibrinolytic agent and prothrombotic clotting factors. ${ }^{[39]}$ Highquality evidence is lacking for these interventions.

Warfarin has three distinct advantages over these drugs: no dose adjustment is required when treating patients with renal failure, therapeutic monitoring is readily accessible, and the antidote is readily available.

\section{Cost and cost-effectiveness}

In a resource-constrained setting such as SA, costs need to be balanced against efficacy and quality of life. This is determined by the costeffectiveness ratio (CER) per quality-adjusted life year (QALY). A CER of $<50000$ USD is considered desirable and a CER $>100000$ USD is considered less desirable. In the UK, a CER of $<30000$ GBP is desirable. ${ }^{[40]}$ Published cost-effectiveness analyses have been conducted using mostly Markov decision models and estimated costs. Harrington et al. ${ }^{[41]}$ concluded that dabigatran, rivaroxaban and apixaban are all cost-effective alternatives to warfarin, with none of these drugs having a CER of $>100000$ USD. Freeman et al. ${ }^{[42]}$ concluded that high-dose dabigatran had a CER of USD45 372 per QALY, and Shah and Gage ${ }^{[43]}$ calculated the CER at USD86 000 per QALY.

In 2013, Coyle et al. ${ }^{[44]}$ conducted one of the first cost-effectiveness analyses of the three new anticoagulants apixaban, dabigatran and rivaroxaban. They came to a similar conclusion as previous authors, with high-dose dabigatran the dominant treatment option and a costeffective alternative to warfarin at a CER of USD20 797. Apixaban was considered as a cost-effective alternative at a CER of USD24 312. Lowdose dabigatran and rivaroxaban were found to have an unfavourable cost-effectiveness analysis, with a CER of $>50000$ USD. ${ }^{[44]}$ Canestaro et al. ${ }^{[4]}$ published a cost-effectiveness analysis that concluded that the only cost-effective treatment option was apixaban. In their analyses the CERs of apixaban, rivaroxaban and dabigatran were USD93 063, USD111 465 and USD140 557, respectively. Their results were in contrast to previous published studies and concluded that both dabigatran and rivaroxaban, although contributing significantly to QALYs, were not cost-effective treatment options. These results are largely due to the authors assigning a price of USD4 per month for warfarin, in contrast to other authors who assigned it a cost of USD30 per month. ${ }^{[45]}$ These studies affirm that there is still much uncertainty when determining whether these drugs are cost-effective alternatives to warfarin. Reasons for this uncertainty include authors using different patient populations and assigning different costs under different economic climates. Table 4 compares the cost-effectiveness studies used in this review.

As a by-product of the cost-effectiveness analyses, these studies did emphasise one important point: that the DOACs provide patients with a superior quality of life compared with warfarin. QALYs gained varied between different studies, but it appears that the DOACs were consistently superior to warfarin regardless of individual $\mathrm{CHADS}_{2}$ scores. ${ }^{[41,42,46]}$ In their base-case analysis, Harrington et al. ${ }^{[41]}$ calculated that dabigatran $150 \mathrm{mg}$ added 8.41 QALYs and apixaban $5 \mathrm{mg}$ 8.47 QALYs compared with 7.97 QALYs for dose-adjusted warfarin. This is in keeping with the results of Freeman et al. ${ }^{[42]}$ who concluded that high-dose dabigatran contributed an additional 0.56 QALYs in comparison with warfarin. Rivaroxaban $20 \mathrm{mg}$ was found to contribute 0.22 QALYs when compared with dose-adjusted warfarin. ${ }^{[46]}$ These findings are broadly in keeping with the results of Coyle et al. ${ }^{[44]}$ who showed that dabigatran $150 \mathrm{mg}$ was the dominant treatment option in terms of QALYs and CER, followed closely by apixaban, rivaroxaban and dabigatran $110 \mathrm{mg}$.

\section{Cost implications for SA}

Little research has been conducted on the cost-effectiveness of the DOACs in an SA setting. Bergh et al. ${ }^{[47]}$ conducted a cost-effectiveness analysis of dabigatran as first-line therapy for stroke prevention in $\mathrm{AF}$ in the SA private sector. They estimated an incremental CER of ZAR93 290 per QALY when comparing dose-adjusted warfarin with dabigatran. They concluded that dabigatran is a cost-effective alternative to warfarin in the SA private sector. ${ }^{[47]}$ Their economic appraisal is useful, but it is difficult to interpret in the context of the SA public sector. No threshold amount exists for willingness to pay per QALY in SA. If one were to convert the current US threshold of USD100 000 to ZAR, at the exchange rate at the time of writing (ZAR13.50 per USD, 15 December 2017), South Africans would be expected to pay ZAR1 350000 per QALY gained. In a country with an unemployment rate of $27.7 \%$, ZAR93 290 per QALY would be unaffordable for a large portion of the population. ${ }^{[48]}$ Symons ${ }^{[49]}$ appears to have come to a similar conclusion in his review article, stating that for the time being the DOACs are too expensive to introduce in the vast majority of SA population groups. These findings are in keeping with our own cost-effectiveness analysis. Warfarin was found to be significantly more cost-effective than the DOACs, even when a wide range of warfarin-related expenses was included. ${ }^{[23]}$

\section{Study limitations}

This review is not intended to be a comprehensive account of all available literature on anticoagulants, but rather to highlight the difficulties and limitations associated with prescribing anticoagulants in SA and to provide some clarity to the clinician.

The major limitation of this review is the paucity of SA literature. The context in which care is rendered in developed countries differs from that in SA, and implementing their recommendations in our public healthcare setting would inevitably prove challenging. The international literature and research on this topic are constantly evolving, so the potential for research included in this review to become outdated is a further limiting factor.

\section{Conclusions}

Anticoagulation is an ever-evolving area with constant updates on new drugs and management protocols. The challenge for doctors in SA is the lack of substantive data to support the use of the DOACs for the majority of patients who access care in the public sector. For the foreseeable future, warfarin will remain the mainstay of oral anticoagulation. It is inexpensive and readily available, and doctors are comfortable prescribing it. However, doctors should familiarise themselves with the DOACs, as they have distinct advantages over warfarin and their availability will increase as cheaper generic alternatives become available.

Acknowledgements. DJL thanks his wife Dr R Laäs for assisting with editing. Author contributions. DJL was the principal investigator and MN the research supervisor.

Funding. A research grant was obtained from the South African Medical Association. The authors state that this grant had no influence on the results and conclusions of this article.

Conflicts of interest. None. 


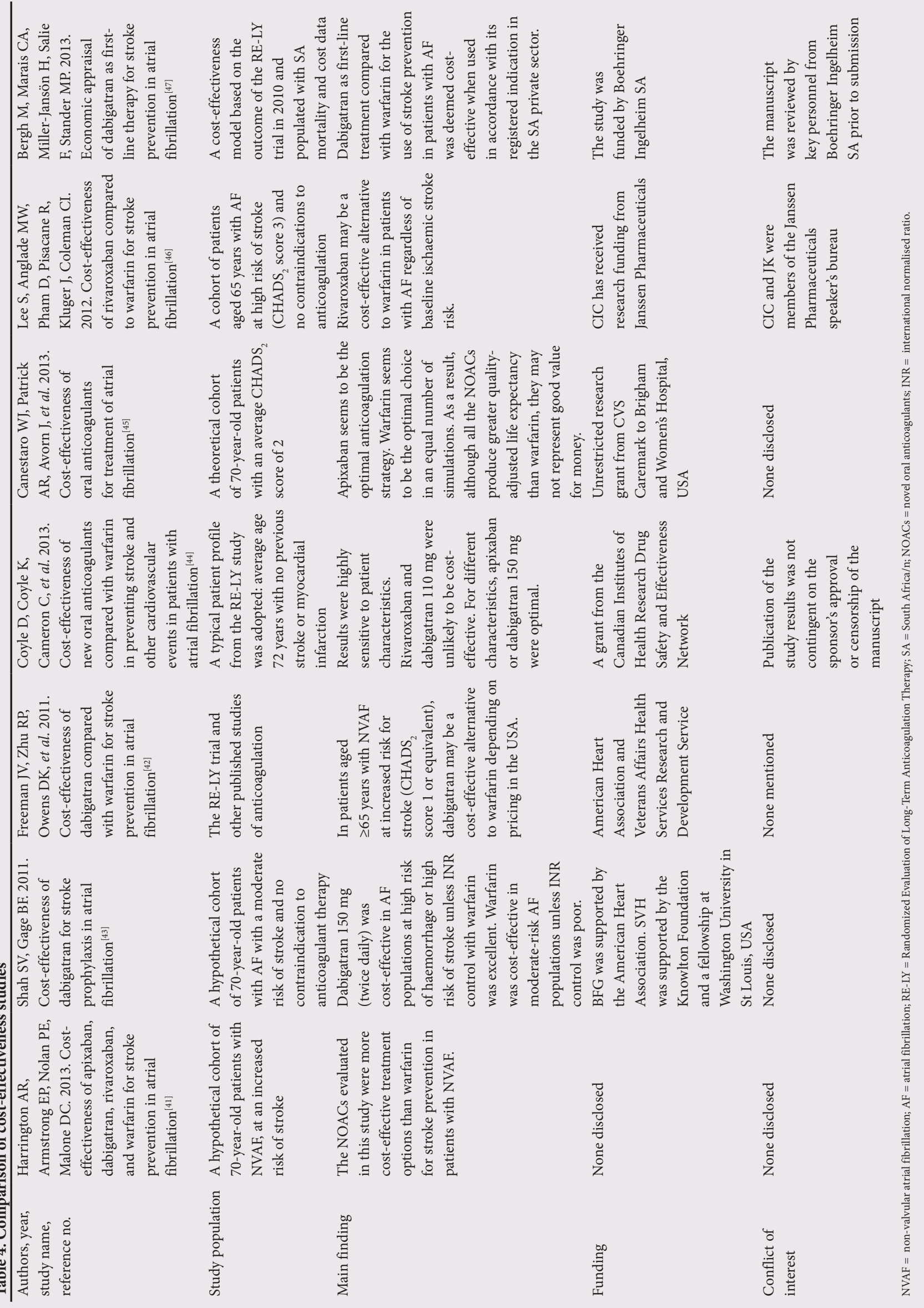


1. Chugh SS, Havmoeller R, Narayanan K, et al. Worldwide epidemiology of atrial fibrillation: A global burden of disease 2010 study. Circulation 2014;129(8):837-847. https://doi.org/10.1161/ global burden of disease 2010
CIRCULATIONAHA.113.005119

2. Neal MJ. Medical Pharmacology at a Glance. 6th ed. Chichester, West Sussex: Wiley-Blackwell, 2009:44-45.

3. Moher D, Liberati A, Tetzlaff J, Altman DG, The PRISMA Group. Preferred Reporting Items for Systematic Reviews and Meta-analyses: The PRISMA Statement. PLoS Med 2009;6(7):e1000097. https://doi.org/10.1371/journal.pmed.1000097

4. Friedman PA, Rosenberg RD, Hauschka PV, Fitz-James A. A spectrum of partially carboxylated prothrombins in the plasmas of coumarin-treated patients. Biochim Biophys Acta 1977;494(1):271276. https://doi.org/10.1016/0005-2795(77)90155-6

5. Ageno W, Gallus AS, Wittkowsky A, Crowther M, Hylek EM, Palareti G. Oral anticoagulant therapy: Antithrombotic Therapy and Prevention of Thrombosis, 9th ed.: American College of Chest Physicians Evidence-based Clinical Practice Guidelines. Chest 2012;141(2 Suppl):e44S-e88S. https://doi. org $/ 10.1378 /$ chest.11-2292

6. Kirkwood TBL. Calibration of reference thromboplastins and standardisation of the prothrombin time ratio. Thromb Haemost 1983;49(3):238-244.

7. Holbrook A, Schulman S, Witt DM, et al. Evidence-based management of anticoagulant therapy: Antithrombotic Therapy and Prevention of Thrombosis, 9th ed: American College of Chest Physicians Antithrombotic Therapy and Prevention of Thrombosis, 9th ed: American College of Chest Physicians
Evidence-Based Clinical Practice Guidelines. Chest 2012;141(2 Suppl):e152S-e184S. https://doi. Evidence-Based Clinical
org $/ 10.1378 /$ chest.11-2295

8. Samsa GP, Matchar DB. Relationship between test frequency and outcomes of anticoagulation: A literature review and commentary with implications for the design of randomized trials of patient selfmanagement. J Thromb Thrombolysis 2000;9(3):283-292. https://doi.org/10.1023/A:1018778914477

9. Lurie Y, Loebstein R, Kurnik D, Almog S, Halkin H. Warfarin and vitamin K intake in the era of pharmacogenetics. Br J Clin Pharmacol 2010;70(2):164-170. https://doi.org/10.1111/j.13652125.2010.03672.x

10. O'Reilly RA. The stereoselective interaction of warfarin and metronidazole in man. N Engl J Med 1976;295(7):354-357. https://doi.org/10.1056/NEJM197608122950702

11. O'Reilly RA. Lack of effect of fortified wine ingested during fasting and anticoagulant therapy. Arch Intern Med 1981;141(4):458-459. https://doi.org/10.1001/archinte.1981.00340040054017

12. Thijssen HHW, Soute BA, Vervoort LM, Claessens JG. Paracetamol (acetaminophen) warfarin interaction: NAPQI, the toxic metabolite of paracetamol, is an inhibitor of enzymes in the vitamin K cycle. Thromb Haemost 2004;92(4):797-802. https://doi.org/10.1160/TH04-02-0109

13. Cropp JS, Bussey HI. A review of enzyme induction of warfarin metabolism with recommendations for patient management. Pharmacotherapy 1997;17(5):917-928. https://doi.org/10.1002/j.1875-9114.1997.
pats JS Bussey HI. A review of enzyme induction of warfarin metabolism with recommendations for patient man

14. Hughes CA, Freitas A, Miedzinski LJ. Interaction between lopinavir/ritonavir and warfarin. CMAJ 2007;177(4):357-359. https://doi.org/10.1503/cmaj.061284

15. University of Liverpool. HIV drug interactions. https://www.hiv-druginteractions.org/checker (accessed 23 December 2017).

16. University of California. HIV InSite. http://arv.ucsf.edu/insite?page $=a r-00-02 \& p$ st $=8 \& p a r a m=120$ (accessed 23 December 2017).

17. Stangier J. Clinical pharmacokinetics and pharmacodynamics of the oral direct thrombin inhibitor dabigatran etexilate. Clin Pharmacokinet 2008;47(5):285-295. https://doi.org/10.2165/00003088200847050-00001

18. Dager WE, Gosselin RC, Kitchen S, Dwyre D. Dabigatran effects on the international normalized ratio, activated partial thromboplastin time, thrombin time, and fibrinogen: A multicenter, in vitro study. Ann Pharmacother 2012;46(12):1627-1636. https://doi.org/10.1345/aph.1R179

19. Bounameaux H, Reber G. New oral antithrombotics: A need for laboratory monitoring. Against. J Thromb Haemost 2010;8(4):627-630. https://doi.org/10.1111/.1538-7836.2010.03759.

20. Samama MM. The mechanism of action of rivaroxaban - an oral, direct factor Xa inhibitor -

compared with other anticoagulants. Thromb Res 2011;127(6):497-504. https://doi.org/10.1016/j.
. compared with othe

21. Guyatt GH, Akl EA, Crowther M, Gutterman DD, Schuünemann HJ. Executive summary: Antithrombotic Therapy and Prevention of Thrombosis, 9th ed: American College of Chest Physicians Evidence-Based Clinical Practice Guidelines. Chest 2012;141(2 Suppl):7S-47S. https://doi.org/10.1378/ chest.1412S3

22. Keeling DM, Baglin T, Tait C, et al. Guidelines on oral anticoagulation with warfarin - fourth edition. Br J Haematol 2011;154(3):311-324. https://doi.org/10.1111/j.1365-2141.2011.08753.x

23. Laäs D, Naidoo M. An evaluation of warfarin usage of an urban district level hospital in KwaZuluNatal. S Afr Med J 2018 (in press).

24. Joint United Nations Programme on HIV/AIDS (UNAIDS). South Africa. http://www.unaids.org/en/ regionscountries/countries/southafrica (accessed 23 December 2017)

25. Awolesi D, Naidoo M, Cassimijee MH. The profile and frequency of known risk factors or comorbidities Awolesi D, Naidoo M, Cassimijee MH. The profile and frequency of known risk factors or comorbidities
for deep vein thrombosis in an urban district hospital in KwaZulu-Natal. South Afr J HIV Med 2016;17(1):a425. https://doi.org/10.4102/sajhivmed.v17i1.425
26. Friberg L, Rosenqvist M, Lip GYH. Evaluation of risk stratification schemes for ischaemic stroke and bleeding in 182678 patients with atrial fibrillation: The Swedish Atrial Fibrillation cohort study. Eur Heart J 2012;33(12):1500-1510. https://doi.org/10.1093/eurheart//ehr488

27. Lip GYH, Nieuwlaat R, Pisters R, Lane DA, Crijns HJGM. Refining clinical risk stratification for predicting stroke and thromboembolism in atrial fibrillation using a novel risk factor-based approach: The Euro stroke and thromboembolism in atrial fibrillation using a novel risk factor-based approach: The

28. Lip GYH, Nielsen PB. Should patients with atrial fibrillation and 1 stroke risk factor $\left(\mathrm{CHA}_{2} \mathrm{DS}_{2}\right.$-VASC $\mathrm{Lip}$ GYH, Nielsen PB. Should patients with atrial fibrillation and 1 stroke risk factor $\left(\mathrm{CHA}_{2} \mathrm{DS}_{2}\right.$ - $\mathrm{VASC}$
score 1 in men, 2 in women $)$ be anticoagulated? Yes: Even 1 stroke risk factor confers a real risk of stroke. score 1 in men, 2 in women) be anticoagulated? Yes: Even 1 stroke risk factor confers a real r
Circulation 2016;133:1498-1503. https://doi.org/10.1161/CIRCULATIONAHA.115.016713

29. Pisters R, Lane DA, Nieuwlaat R, de Vos CB, Crijns HJGM, Lip GYH. A novel user-friendly score (HAS BLED) to assess 1-year risk of major bleeding in patients with atrial fibrillation: The Euro Heart Survey. BLED) to assess 1-year risk of major bleeding in patients with atrial
Chest 2010;138(5):1093-1100. https://doi.org/10.1378/chest.10-0134

30. Eikelboom JW, Connolly SJ, Brueckmann M, et al. Dabigatran versus warfarin in patients with mechanical heart valves. N Engl J Med 2013;369(13):1206-1214. https://doi.org/10.1056/NEJMoa1300615

31. Hylek EM. Dabigatran and mechanical heart valves - not as easy as we hoped. N Engl J Med 2013;369(13):1264-1266. https://doi.org/10.1056/NEJMe131039

32. Carnicelli AP, de Caterina R, Halperin JL, et al. Edoxaban for the prevention of thromboembolism in patients with atrial fibrillation and bioprosthetic valves. Circulation 2017;135(13):1273-1275. https://doi org/10.1161/CIRCULATIONAHA.116.02671

33. Patel MR, Mahaffey KW, Garg J, et al. Rivaroxaban versus warfarin in nonvalvular atrial fibrillation. N Engl J Med 2011;365(10):883-891. https://doi.org/10.1056/NEJMoa1009638

34. Granger $\mathrm{CB}$, Alexander $\mathrm{JH}, \mathrm{McMurray} J \mathrm{~J}$, et al. Apixaban versus warfarin in patients with atrial fibrillation N Engl J Med 2011;365(11):339-354. https://doi.org/10.1056/NEJMoa1107039

5. Connolly SJ, Ezekowitz MD, Yusuf S, et al. Dabigatran versus warfarin in patients with atrial fibrillation N Engl J Med 2009;361(12):1139-1151. https://doi.org/10.1056/NEJMoa090556

36. Connolly SI, Pogue J, Eikelboom J, et al. Benefit of oral anticoagulant over antiplatelet therapy in atrial fibrillation depends on the quality of international normalized ratio control achieved by centers and countries as measured by time in therapeutic range. Circulation 2008;118(20):2029-2137. https.//dol org/10.1161/CIRCULATIONAHA.107.750000

37. Boehringer Ingelheim Pharmaceuticals I. Praxbind [package insert]. https://docs.boehringer-ingelheim. com/Prescribing\%20Information/PIs/Praxbind/Praxbind.pdf (accessed 29 June 2018).

38. South Africa. Medicines and Related Substances Act 101 of 1965. http://www.hpcsa.co.za/Uploads/editor/ UserFiles/downloads/legislations/acts/medicines_and_related_sub_act_101_of_1965.pdf (accessed 24 December 2017).

39. Steiner T, Bohm M, Dichgans $M$, et al. Recommendations for the emergency management of complications associated with the new direct oral anticoagulants (DOACs), apixaban, dabigatran and rivaroxaban. Clin Res Cardiol 2013;102(6):399-412. https://doi.org/10.1007/s00392-013-0560-7

40. Cohen DI, Reynolds MR. Interpreting the results of cost-effectiveness studies. J Am Coll Cardiol 2008;52(25):2119-2126. https://doi.org/10.1016/j.jacc.2008.09.018

41. Harrington AR, Armstrong EP, Nolan PE, Malone DC. Cost-effectiveness of apixaban, dabigatran rivaroxaban, and warfarin for stroke prevention in atrial fibrillation. Stroke 2013:44(6):1676-1681 https:// rivaroxaban, and warfarin for stroke prevent

42. Freeman JV, Zhu RP, Owens DK, et al. Cost-effectiveness of dabigatran compared with warfarin for strok prevention in atrial fibrillation. Ann Intern Med 2011;154(1):1-11. https://doi.org/10.7326/0003-4819 154-1-201101040-00289

43. Shah SV, Gage BE. Cost-effectiveness of dabigatran for stroke prophylaxis in atrial fibrillation. Circulatio 2011;123(22):2562-2570. https://doi.org/10.1161/CIRCULATIONAHA.110.98565

44. Coyle D, Coyle K, Cameron C, et al. Cost-effectiveness of new oral anticoagulants compared with warfarin in preventing stroke and other cardiovascular events in patients with atrial fibrillation. Value Health 2013;16(4):498-506. https://doi.org/10.1016/j.jval.2013.01.009

45. Canestaro WJ, Patrick AR, Avorn J, et al. Cost-effectiveness of oral anticoagulants for treatment of atrial fibrillation. Circ Cardiovasc Qual Outcomes 2013;6(6):724-731. https://doi.org/10.1161/ CIRCOUTCOMES.113.00066

46. Lee S, Anglade MW, Pham D, Pisacane R, Kluger J, Coleman CI. Cost-effectiveness of rivaroxaban compared to warfarin for stroke prevention in atrial fibrillation. Am J Cardiol 2012;110(6):845-851. https://doi.org/10.1016/j.amjcard.2012.05.011

47. Bergh M, Marais CA, Miller-Jansön H, Salie F, Stander MP. Economic appraisal of dabigatran as firstline therapy for stroke prevention in atrial fibrillation. S Afr Med J 2013:103(4):241-245. https://do. org/10.7196/SAMJ.6471

48. Statistics South Africa. Quarterly Labour Force Survey - QLFS Q3:2017. http://www.statssa.goy. $\mathrm{za} /$ ? $\mathrm{p}=10658$ (accessed 15 December 2017).

49. Symons G. Anticoagulation: Where have we come from and where are we going? The evidence for and against novel anticoagulants. S Afr Med J 2014;104(2):143-146. https://doi.org/10.7196/SAMJ.7873 